\title{
DIFERENCIAS EN EL USO DE LOS PROGRAMAS DE RENTAS MÍNIMAS SEGÚN NACIONALIDAD La Renta de Garantía de Ingresos en la Comunidad Autónoma vasca
}

\author{
DIFFERENCES IN THE USE OF MINIMUM INCOME PROGRAMS BY \\ NATIONALITY \\ Income Revenue Assurance in the Basque Country
}

\author{
CRIStina LaVia Martínez cristina.lavia@ehu.es \\ Universidad del País Vasco, España.
}

Gorka Moreno MÁrQUEZ gorka.moreno@ehu.es

Universidad del País Vasco, España.

\author{
Xabier Aierdi URraza xabier.aierdi@ehu.es \\ Universidad del País Vasco, España.
}

\begin{abstract}
RESUMEN
En este artículo realizamos un primer análisis de la base de datos de personas perceptoras de la prestación de la Renta de Garantía de Ingresos -el programa de rentas mínimas en la Comunidad Autónoma del País Vasco (CAPV) - en Vizcaya entre 2004 y 2010, con el objeto de probar una serie de indicadores básicos para la descripción del colectivo y, especialmente, para la comparación de las poblaciones autóctona e inmigrante. Además de conocer las características de ambos colectivos e identificar pautas diferenciales sobre su presencia en la prestación, el objetivo último radica en contribuir a contrastar algunas percepciones existentes en torno al uso de las prestaciones sociales por parte del colectivo inmigrante. Entre los resultados podemos destacar diferencias entre ambos colectivos en lo referente a los perfiles sociodemográficos en aspectos tales como la edad, el sexo, estado civil o municipio de residencia. Por otra parte, se analizan aspectos como la duración de las estancias y se detecta una mayor percepción económica por parte de la población extranjera. También se recurre a unos índices para identificar las situaciones de cronicidad (máxima percepción ininterrumpida durante al menos dos años), los cuales revelan también una situación crecientemente más desfavorable entre los extranjeros e incluso permiten reconocer a algunos colectivos nacionales que destacan más (rumanos y africanos subsaharianos).
\end{abstract}

Palabras Clave

Exclusión social; Inmigración; Políticas sociales; Rentas mínimas.

\section{ABstract}

This article makes a study of the recipients of the minimum income scheme existing in the Autonomous Community of the Basque Country, a region in Spain. For this purpose we analyze the data on this program's recipients during the period from 2004 to 2010, with the aim of testing a series of basic indicators for describing this collective and especially for comparing the autochthonous and immigrant populations. Besides determining the characteristics of the two collectives and identifying differential patterns on their presence in benefit 
provision, the final aim is to contribute to comparing certain existing perceptions on the use of social benefits by the immigrant collective. In the results we underscore differences between the socio-demographic profiles of the two collectives in aspects like age, sex, marital status or municipality of residence. At the same time, we analyze aspects like the duration of the period receiving benefits and we detect a greater receipt of social benefits by the foreign population. We also employ certain indices for identifying states of chronicity (maximum uninterrupted receipt for at least two years), which also reveal an increasingly unfavorable situation amongst foreigners and even make it possible to identify certain national collectives that stand out due to their greater chronicity - Romanians and sub-Saharan Africans.

\section{KEYWORDS}

Immigration; Minimum Incomes; Social Exclusion; Social Policy.

\section{INTRODUCCIÓN}

En la actualidad uno de los temas que más controversia crea en torno a la cuestión de la inmigración es el uso de las prestaciones sociales y de los recursos de protección social, en general, por parte de este colectivo. En diferentes estudios sobre actitudes y percepciones hacia la inmigración aparece claramente delimitado este debate y se muestra cómo entre la población autóctona prevalecen las percepciones que subrayan que las personas inmigrantes hacen un uso indebido y excesivo de estas prestaciones, sobre todo en lo tocante a las de carácter económico (Cea D'Ancona y Vallés 2009 y 2010; Rinken y Pérez Yruela 2007; Rinken et al. 2009; Ikuspegi 2009 y 2011). Estas evidencias se intensifican aún más en un contexto de crisis económica como el presente, en el que, por un lado, la necesidad de prestaciones sociales se acrecienta y, por otro, se están adoptando medidas de recorte y restricción de las mismas.

En líneas generales, el nexo entre inmigración y virtual uso indebido de prestaciones sociales está suponiendo una importante deslegitimación de algunas de estas prestaciones sociales o sistemas de protección, e incluso están haciendo que sea el propio sistema en su conjunto el que se esté impugnando y poniendo en duda. Ahora bien, más allá de la detección de estas percepciones, realmente no existen muchos estudios que se centren en este ámbito y que realicen un exhaustivo análisis de los datos existentes al respecto, y que puedan dar más luz en torno a si existe un uso diferencial por parte del colectivo inmigrante y autóctono, si la población inmigrante permanece más en las prestaciones o si comete fraude con más frecuencia que la autóctona.

En algunos estudios anteriores (Moreno y Aierdi 2008; Alemán 2010) y basándonos en los pocos datos secundarios disponibles, hemos planteado la posibilidad de que los servicios sociales - y las prestaciones sociales - jueguen un papel diferente para uno y otro colectivo. La hipótesis sería que, mientras la población autóctona utiliza los sistemas de protección social como confirmación de un proceso de movilidad social descendente y a modo de "última red de protección", la extranjera lo hace como "primer trampolín para la inserción" y en los primeros momentos del proyecto migratorio. Estos diferentes usos también tendrían su impacto en aspectos como la estancia o la cronicidad en la prestación. Más concretamente, si la utilización de estos servicios sociales por parte de 
la población autóctona tiende a cronificarse, en el caso de la población extranjera su uso sería más limitado en el tiempo.

Con este artículo queremos profundizar en esta línea de trabajo para avanzar en el contraste de tales hipótesis y particularmente vamos a aportar alguna evidencia empírica a partir del análisis de datos directos sobre perceptores de prestaciones sociales según nacionalidad. Concretamente, vamos a ofrecer resultados sobre el análisis de datos de las personas perceptoras de Renta de Garantía de Ingresos - RGI en adelante- en Vizcaya durante el periodo 2004-2010. El análisis procede de la explotación estadística específica de las bases de datos originales que fueron cedidas para este fin por el Departamento de Acción Social de la Diputación Foral de Vizcaya1.

Hemos optado por centrarnos en la RGI, el programa de Rentas Mínimas del País Vasco, debido a sus características: es una prestación de carácter económico que suscita mayor debate que otras de carácter material, pero cuyos costos parecen pasar desapercibidos, como por ejemplo la sanidad o la educación. Por otro lado, es una medida muy relevante para la lucha contra la pobreza y la exclusión social en la Comunidad Autónoma del País Vasco. Todo ello hace que el impacto, tanto mediático como en la opinión pública, haya sido y sea alto. De hecho, es la prestación social del País Vasco que suscita mayor debate en torno a la supuesta utilización masiva y abusiva de la misma por parte del colectivo inmigrante. Al respecto, según los últimos datos del estudio sobre actitudes y opiniones de la población autóctona hacia la inmigración que realiza anualmente el Observatorio Vasco de Inmigración, un $57,6 \%$ de la población vasca está de acuerdo con la afirmación de que la población inmigrante se aprovecha excesivamente de la RGI, frente al $24 \%$ que es contraria a dicha idea. Unido a estos datos, un $9 \%$ cree que las personas inmigrantes no tendrían que tener derecho a esta prestación, mientras que un $57,1 \%$ demanda algún tipo de restricción en el acceso para este colectivo -situación administrativa regular o prioridad de personas autóctonas-(Ikuspegi 2013).

Con respecto a la estructura del artículo, en el siguiente apartado realizamos un breve acercamiento conceptual a los programas de rentas mínimas -minimum income schemes- a nivel europeo, estatal y autonómico, haciendo especial hincapié en el programa que nos atañe, el de la Renta de Garantía de Ingresos del País Vasco. Posteriormente especificaremos las características metodológicas y el alcance de los análisis realizados, para pasar al apartado de presentación de resultados, en el que se aportan los hallazgos más interesantes sobre la presencia de extranjeros entre los perceptores de la RGI en Vizcaya entre 2004-2010 y sus características, en comparación con las de los perceptores autóctonos. Se ofrece un perfil sociodemográfico de los perceptores y en función de su nacionalidad, y también se aporta un análisis comparativo de las características diferenciales de su "estancia" en la prestación. En este sentido, queremos profundizar en las diferencias que muestran ambos colectivos en aspectos como el alcance

\footnotetext{
1 "Acuerdo de Regularización del acceso y/o Tratamiento de Datos de Carácter Personal" del Departamento de Acción Social de la Diputación Foral de Vizcaya con Ikuspegi-Observatorio Vasco de Inmigración.
} 
o cobertura de la prestación, la cuantía económica que perciben, o su continuidad en la misma. Finalmente exponemos también los resultados de la aplicación de una elaboración experimental de indicador para medir la cronicidad de los perceptores.

De algún modo todos estos indicadores arrojan luz sobre los usos diferenciales de la RGI por ambos colectivos, aunque los datos analizados también tienen limitaciones. Tras los resultados se recogen los resultados más importantes en las conclusiones, así como algunas reflexiones que parten de estos.

\section{Los PROGRAMAS dE RENTAS MíNIMAS EN EUROPA. El CASO VASCO}

Los programas de rentas mínimas son en la actualidad, y ya desde hace dos décadas (Comisión Europea 2003; Castel 1997), una de las herramientas más relevantes para la lucha contra la pobreza y la exclusión social a nivel europeo (Peña-Casas 2005; European Comission 2006; Saraceno 2010; Euzéby 2012) y para paliar los efectos de estos (Frazer y Marlier 2009). De este modo, en la actualidad, la mayoría de los países de la Unión Europea disponen de algún mecanismo de rentas mínimas (Da Roit y Crepaldi 2007).

Estos programas tienen un carácter estatal y es destacable la gran heterogeneidad de los mismos (Cantillon, Van Mechelen y Schulte 2008; Figari, Haux, Matsaganis y Sutherland 2010; Immervoll 2012; Yacut-Cakar, Erus y Adaman 2012; Figari, Matsaganis y Sutherland 2013), que se refleja en aspectos tales como la cobertura, la cuantía económica (Behrendt 2003; Euzéby 2004; Busilacchi 2008), la puesta en marcha y el desarrollo posterior de los diferentes programas (Guibentif y Bouget 1997; Matsaganis, Ferrera, Capucha y Moreno 2003; Barr 2004; Rat 2009) o la eficacia de los mismos (Nelson 2010; Van Mechelen Marchal, Goedemé, Marx y Cantillon 2011).

Por citar algunas de estas diferencias, mientras que en Luxemburgo una persona recibe en el programa de rentas mínimas 1641 euros, esta cifra es de 123 en Bulgaria (European Parlament 2010). Incluso en la respuesta a la crisis también se pueden ver grandes diferencias. Así, mientras que en algunos países se ha reforzado la cobertura, (por lo menos en la primera fase de la crisis), para así poder dar una respuesta adecuada a la situación de la población, en otros como el Reino Unido y Holanda se ha optado por los recortes, e incluso, en Irlanda, el programa de rentas mínimas ha desaparecido (Marchal, Marx y Van Mechelen 2011). De igual forma, a nivel europeo, es destacable la iniciativa, aprovechando el Año europeo de lucha contra la Pobreza -2010_, para la elaboración de una directiva común en materia de rentas mínimas para el conjunto de la Unión, que fue llevada al Parlamento Europeo y que fue rechazada por 344 votos frente a 262.

Con respecto al modelo español de rentas mínimas es resaltable su carácter autonómico, de tal forma que no existe un único modelo de carácter estatal y cada Comunidad Autónoma ha desarrollado el propio. De esta forma, el sistema español de rentas mínimas se caracteriza por su heterogeneidad (Arriba 1999; Roberts 2001; Gaviria y Gonzá- 
lez 2002) y por su gran variabilidad. De hecho, la mayoría de programas autonómicos no cumplen los requisitos para ser considerados como programas de rentas mínimas tal y como se entienden a nivel europeo. En palabras de Miguel Laparra, para un $80 \%$ de la población española no existen realmente programas de rentas mínimas (Laparra 2004) y tan solo se puede hablar de estos en Comunidades Autónomas como el País Vasco, Navarra, Madrid o Asturias (Laparra y Ayala 2009). Así, la mayoría de programas no consiguen ofrecer la cobertura adecuada para superar el umbral de la pobreza (Rodríguez Cabrero 2009).

En este artículo, en concreto, se analizan los datos del programa de rentas mínimas existente en la Comunidad Autónoma del País Vasco, que se inició en el año 1989 bajo el influjo del modelo francés de rentas mínimas — Revenu Minimum D'Insertion-. Es el programa más importante en España en lo tocante a la cuantía, la cobertura o la efectividad del mismo, y es conocido como Renta de Garantía de Ingresos - RGI - y el único que puede equipararse a los existentes en la mayoría de países europeos (Moreno, Matsaganis, Ferrera y Capucha 2003; Laparra, 2004b).

Entre sus características principales cabe destacar que la RGI es un derecho subjetivo al que pueden acceder aquellas personas residentes en la CAPV durante al menos los últimos tres años, tengan más de 23 años, hayan constituido una unidad de convivencia independiente al menos un año antes de solicitar la prestación y posean unos ingresos mensuales menores a los establecidos para su categoría -en torno a unos 650 euros para una unidad de convivencia de carácter unipersonal- También es destacable que no existe un límite máximo de estancia en el programa, de tal modo que aunque en la normativa se prevé una revisión bianual de la situación de la persona perceptora, la prestación se percibe mientras se sigan cumpliendo los requisitos que hemos apuntado a lo largo de este párrafo.

La heterogeneidad del modelo español, así como la preponderancia del vasco pueden verse a través de algunos datos referidos al presupuesto de los programas 0 al número de personas perceptoras. Así, según los datos del Ministerio de Trabajo y Asuntos Sociales para el año 2005, el programa vasco ofrecía una cobertura seis veces superior a la media estatal (Ministerio de Trabajo y Asuntos Sociales 2005). De igual forma, se estimaba que, justo antes de la crisis, en torno a un tercio del total de las personas perceptoras de rentas mínimas en España lo hacían en la CAPV (Laparra y Ayala 2009: 32). El hecho de que la RGI sea un derecho subjetivo, junto a la debilidad del resto de programas (Arriba y Guinea 2008) y el recorte de la prestación en algunos de ellos, nos hace pensar que en plena crisis no es descabellado pensar que esta cifra se sitúe en torno al $50 \%$ del total. Dicho de otra forma, la mitad de los perceptores de rentas mínimas en España residen en el País Vasco. Este es un dato realmente llamativo, si tenemos en cuenta que el peso de dicha Comunidad Autónoma sobre la población estatal es de un $4,6 \%$ y que además la tasa de pobreza es sensiblemente más baja que la media estatal.

Estas cifras se explican en gran parte debido a las características del programa vasco, que muestra una cobertura mayor y unas restricciones menores con respecto a 
otros programas autonómicos. La inmensa mayoría de estos no son un derecho subjetivo - Valencia, Murcia, etc.-, lo que hace que la cuantía destinada a esta partida sea mucho menor. De igual forma, son muy pocos los programas que se extienden a las personas mayores de 65 años, en situación administrativa irregular, o que son compatibles y complementarios a otras prestaciones que se reciben previamente. En todo caso, es difícil poder hacer comparaciones y análisis conjuntos de los diferentes programas debido a la variabilidad y en muchos casos a la escasez de datos (Arriba 2009).

A pesar de su relevancia y sus peculiaridades dentro del contexto español, más allá de algún trabajo realizado por el propio Gobierno Vasco sobre perceptores de la prestación (2008), no existen grandes estudios 0 análisis que profundicen en aspectos relacionados con la Renta de Garantía de Ingresos.

\section{Metodología}

Los datos analizados aquí se refieren a perceptores de RGI en Vizcaya durante el periodo que transcurre de 2004 hasta 2010 -mayo-, aunque las bases originales explotadas disponían de datos desde el año 1989. La selección temporal es relativamente arbitraria porque responde al interés de realizar una descripción y comparación de la presencia de población extranjera en la RGI, que no consta entre los perceptores hasta este año de forma significativa. Los datos analizados representan entonces el $74 \%$ de todos los expedientes de solicitantes diferentes que constan desde 1989 y recogen el $99,9 \%$ de los expedientes solicitantes con titular de nacionalidad extranjera, ya que el gran montante de estos últimos llega a la CAPV en estos últimos años y por lo tanto acceden a la RGI también más recientemente. Los titulares de la prestación son los que consideramos aquí como perceptores aunque pueden representar a una unidad familiar con más miembros.

Hay que destacar que la información "bruta" cedida por la Diputación Foral de Vizcaya se componía de dos grandes bases de datos relacionadas: una base que contenía información relativa a "expedientes" (casi 80.000 solicitantes titulares) y otra que contenía la especificación de sus resoluciones (245.000) y en la que se detallaban las características de cada trámite administrativo y prestación. Además de por su volumen, los trabajos previos con las bases de datos fueron especialmente laboriosos ya que su finalidad administrativa complicaba algunas posibilidades de análisis y había que proceder de modo bastante experimental. Dado que las características demográficas explotables iban asociadas a los expedientes, pero las de la prestación iban asociadas a cada resolución y eran mucho más variables, se optó por intentar elaborar unos indicadores descriptivos sencillos, aunque comparables, a cuenta de la agregación de todas las características de la percepción a lo largo de todo el periodo 2004-2010 para cada titular (expediente), y siempre que hubiera habido percepción económica. 
Este análisis define en principio una población de perceptores titulares diferentes que "han recibido la prestación en algún momento" dentro de ese periodo, sea cual sea el número de resoluciones que administrativamente las han sostenido y sea cual sea su "trayectoria" temporal en la RGI.

En definitiva, los datos sociodemográficos correspondientes a los perceptores que se han explotado son los de sexo, edad, nacionalidad, estado civil y municipio de residencia. A efectos de la explotación agregada, la edad del titular se elaboró como edad a la "entrada" en la prestación, es decir, edad en el momento en que percibe RGI por primera vez dentro de este periodo. Por otra parte, se ha extraído y elaborado alguna información sobre las características de la prestación para cada persona titular perceptora considerando siempre la agregación de las prestaciones obtenidas a lo largo del mencionado periodo 2004-10. La información original se refiere al número de pagos mensuales obtenidos y a su cuantía. Poniendo en relación esta información con los máximos posibles de la prestación y con el tiempo durante el que se ha percibido, se han elaborado unos indicadores globales básicos sobre duración, continuidad, cobertura e importe de las prestaciones obtenidas. Finalmente se aporta también una elaboración tentativa de indicadores de "cronicidad" en la prestación basados en los anteriores.

La información obtenida da una imagen de los titulares que "han sido" en algún momento perceptores de RGI en este periodo y solo a cuenta de resoluciones iniciadas a partir de 2004. La idea no es contabilizar el número de beneficiarios ni el volumen de ingresos obtenidos, sino explorar metodológicamente las posibilidades informativas de algunos indicadores-resumen que se pueden aplicar a la información agregada con el fin de obtener alguna descripción de las características básicas del perceptor común.

\section{Resultados}

\section{Perfiles sociodemográficos de las personas perceptoras de RGI (2004/2010)}

Entre enero de 2004 y mayo de 2010 constan 58.016 solicitantes distintos de RGI, de los cuales $51.386(88,6 \%)$ son considerados "perceptores" pues hay datos que confirman el cobro efectivo de la prestación. El perfil de los solicitantes y de los perceptores en las características consideradas viene a ser prácticamente el mismo o, dicho de otra forma, no hay diferencias reseñables de perfiles en el acceso real a la prestación por parte de los solicitantes.

Para tener una referencia general, resumimos a grandes rasgos las características más frecuentes de todo el conjunto de perceptores titulares considerados de la RGI: residentes en Bilbao, mujeres, de edades entre 25 y 44 años, y solteros/as y/o personas que viven solas, y de nacionalidad española. 
- La distribución territorial de la población perceptora de RGI reproduce e incluso acentúa la macrocefalia de la población global del territorio: la inmensa mayoría $(83 \%)$ de los perceptores residen en la comarca capital (Gran Bilbao) y especialmente en el mismo Bilbao (43\%), seguidos en orden por los municipios mayores de la Comarca metropolitana del Gran Bilbao. El 76\% de los perceptores son residentes en los nueve municipios más poblados del Gran Bilbao cuando en términos generales estos absorben poco más que el $65 \%$ de la población vizcaína (Padrón 2009).

- Una clara mayoría (65\%) de los titulares perceptores de la prestación son mujeres, frente a solo un $35 \%$ de hombres. Considerando la edad con la que aparecen por primera vez en el sistema de prestaciones (desde 2004), el grupo más numeroso (28\%) es el formado por titulares de entre 25 y 34 años, que junto con los de 35 a 44 años, el segundo grupo en presencia $(22,5 \%)$, componen la mitad del colectivo (Tabla 1). El cruce de edad y sexo resultó especialmente relevante. La estructura de edad de las mujeres titulares es más variada pero arroja una media más alta (47,6 años frente a 42,2 de los hombres) por el peso de las mujeres de avanzada edad: casi un $25 \%$ de estas tienen más de 64 años, mientras que el grupo principal, de 25 a 34 años, representa el $26 \%$. Para el colectivo de titulares hombres el perfil principal también es el de 25 a 34 años pero más concentrado, con un $31 \%$ de presencia, y solo hay un $11 \%$ de mayores de 64 años. Estas diferencias de datos se explican con base en el tipo de pensiones asociadas a los perfiles de más edad: contributivas en el caso de los hombres y no contributivas y de viudedad entre las mujeres.

- Casi la mitad (48\%) de los titulares perceptores constan en sus expedientes como personas solteras, aunque esa situación es especialmente mayoritaria entre los hombres (tabla 1). Entre las mujeres hay casi tantas viudas como divorciadas y separadas (20-21\%). Aunque los datos disponibles sobre el tamaño de las unidades familiares afectadas eran limitados en las bases originales, sí se pudo identificar que, sobre el total, más de la mitad de las personas perceptoras eran personas solas (53\%).

- Finalmente, de los 51.386 titulares perceptores de RGI desde 2004 hasta mayo de 2010 , solo el $28 \%$ consta que sean extranjeros frente a un $65 \%$ de personas de nacionalidad española, aunque hay un $7 \%$ de titulares de los que se desconoce la nacionalidad. Estos datos se asemejan mucho a los obtenidos en una encuesta del Gobierno vasco realizada en el año 2006 y publicada en el 2008 (Gobierno Vasco 2008). Aunque trabajando sobre un periodo de varios años no es posible (y no era el objetivo de este análisis) poner en relación el número de perceptores sobre el total de población que potencialmente podría haberlo sido, porque ese dato agregado no existe, estos resultados sí permiten concluir que la presencia relativa de población extranjera entre los perceptores es muy superior a su peso relativo en la población global ya que las tasas de extranjería en Vizcaya han oscilado entre un 2,5\% y un 6\% en el periodo 2004-2010. 
Tabla 1.

Perceptores por Edad y por Estado Civil, y según Sexo (\%)

\begin{tabular}{lccc}
\hline & Mujer & Hombre & Total \\
\hline No consta & 0,3 & 0,1 & 0,2 \\
$18-24$ & 8,5 & 7,2 & 8,1 \\
$25-34$ & 25,9 & 31,0 & 27,7 \\
$35-44$ & 20,8 & 25,8 & 22,5 \\
$45-54$ & 11,9 & 16,4 & 13,4 \\
$55-64$ & 8 & 8,3 & 8,1 \\
$65-74$ & 8,4 & 6,1 & 7,6 \\
75 y más años & 16,3 & 5,1 & 12,5 \\
Solteros/as & 41,4 & 60,2 & 47,8 \\
Casados/as y uniones & 17,0 & 28,3 & 20,9 \\
Divorciados/as y separados/as & 20,4 & 8,9 & 16,5 \\
Viudos/as & 21,3 & 2,6 & 14,9 \\
Total & 100 & 100 & 100 \\
\% Sexo & 65,0 & 35,0 & 100 \\
\hline
\end{tabular}

Fuente: Elaboración propia sobre bases Diputación Foral de Bizkaia (DBF).

Tabla 2.

Perceptores por grandes áreas de nacionalidades (\%)

\begin{tabular}{lrcc}
\hline & \% total & \% extranjeros & \% acum.extranjeros \\
\hline Latinoamérica & 15,7 & 56,2 & 56,2 \\
Magreb & 4,3 & 15,4 & 71,5 \\
Resto África & 3,8 & 13,5 & 85,1 \\
Rumanía (UE27) & 2,6 & 9,5 & 94,5 \\
UE15 & 0,6 & 2,1 & 96,6 \\
Resto Europa & 0,5 & 1,9 & 98,5 \\
Resto Asia & 0,3 & 1,1 & 99,6 \\
UE25 (ampliación) & 0,1 & 0,3 & 99,9 \\
China & 0,0 & 0,1 & 99,9 \\
Oceanía & 0,0 & 0,0 & 100 \\
Norteamérica & 0,0 & 0,0 & 100 \\
Total Extranjeros & 27,9 & 100 & - \\
Españoles & 64,8 & - & - \\
No consta & 7,3 & - & - \\
Total & 100,0 & - & - \\
\hline
\end{tabular}

Fuente: Elaboración propia sobre bases Diputación Foral de Bizkaia (DBF). 


\section{Perfiles comparados. Españoles y extranjeros}

Dado su peso en el conjunto, la descripción general de la población de perceptores debería corresponder fundamentalmente a las características de los titulares españoles. Como se verá, los perceptores extranjeros se diferencian significativamente en sus características básicas: son más jóvenes, y, aunque las mujeres titulares son mayoría hay proporcionalmente más hombres y muchísimas más personas solteras o casadas. Tales características tienen mucho que ver con la distribución o composición de los orígenes de los perceptores de nacionalidad extranjera.

Entre los perceptores extranjeros el perfil predominante es mayoritariamente latinoamericano (56\%), seguido de los ciudadanos de países del Magreb (15\%) y del resto de África $(13,5 \%)$. También los ciudadanos de la última ampliación de la UE (rumanos fundamentalmente, ya que la presencia de personas de origen búlgaro es prácticamente inexistente) aparecen representados en un 9,5\% (tabla 2). La distribución geográfica de los extranjeros que perciben la prestación muestra bastante coherencia con respecto al mosaico de nacionalidades más representativas de la inmigración económica en Vizcaya, aunque al tratarse de la agregación de varios años la población latinoamericana resulta algo sobrerrepresentada. En concreto, aparecen ciudadanos de casi 140 nacionalidades diferentes aunque más del $75 \%$ pertenecen a solo $10 \mathrm{y}$, específicamente, los titulares extranjeros más frecuentes (suman casi la mitad) son de Bolivia, Colombia, Marruecos y Rumanía (Tabla 3).

Tabla 3.

Perceptores por nacionalidades principales

\begin{tabular}{lccc}
\hline & $\%$ total & \% extranjeros & \% acum.extranjeros \\
\hline Bolivia & 6,1 & 22,0 & 22,0 \\
Colombia & 3,0 & 10,9 & 32,9 \\
Marruecos & 2,9 & 10,4 & 43,3 \\
Rumanía & 2,6 & 9,2 & 52,4 \\
Brasil & 1,5 & 5,4 & 57,8 \\
Senegal & 1,4 & 5,1 & 62,9 \\
Argelia & 1,2 & 4,1 & 67,1 \\
Paraguay & 1,1 & 4,1 & 71,2 \\
Ecuador & 1,0 & 3,7 & 74,8 \\
Resto (128 nacionalid.) & 7,1 & 25,1 & 100 \\
Total Extranjeros & 27,9 & 100 & \\
Españoles & 64,8 & & \\
No consta & 7,3 & & \\
Total & 100,0 & & \\
\hline
\end{tabular}

Fuente: Elaboración propia sobre bases Diputación Foral de Bizkaia (DBF). 
- En cuanto a la distribución por edad, queda claro (tabla 4) que la población extranjera es sensiblemente más joven que la autóctona y que, mientras un $85,6 \%$ de los primeros entra en la prestación con menos de 44 años, esta cifra es de un $44,5 \%$ para la población autóctona. De igual modo, las personas extranjeras de más de 65 años que han accedido a la RGI suponen un 1,3\% del total frente al $30,1 \%$ de las autóctonas. En consecuencia, la edad media (52 vs. 34 años) a la entrada es significativamente menor para los perceptores extranjeros.

- La distribución diferencial por sexo (hasta un $42 \%$ de hombres entre titulares extranjeros) viene sobre todo por las características particulares de los perceptores africanos (el $72 \%$ son hombres) que representan el $29 \%$ de los extranjeros titulares. Frente a este grupo, tenemos a la mayoría (56\%) del colectivo extranjero, que son las personas de origen latinoamericano y dentro del cual las mujeres son las titulares mayoritarias $(73 \%)$.

- En cuanto a los perfiles según estado civil (Tabla 4) la diferencia viene sobre todo por la mayor variedad de tipos de perceptores entre la población española $y$, en particular, por la participación de dos tipos de titulares que apenas se dan entre los extranjeros: las personas separadas o divorciadas y las viudas (muje-

Tabla 4.

Perceptores según nacionalidad y por sexo, edad, estado civil y lugar de residencia (\%)

\begin{tabular}{lccc}
\hline & Española & Extranjera & Total \\
\hline Mujer & 69,4 & 58,0 & 66,0 \\
Hombre & 30,6 & 42,0 & 34,0 \\
$18-24$ años & 5,3 & 14,7 & 8,1 \\
$25-44$ años & 39,0 & 70,7 & 48,5 \\
$45-64$ años & 25,4 & 13,0 & 21,7 \\
65 y más años & 30,1 & 1,3 & 21,4 \\
Solteros/as & 40,1 & 73,3 & 47,8 \\
Casados/as y uniones & 17,7 & 26,4 & 20,9 \\
Divorciados/as y separados/as & 21,8 & 1,9 & 16,5 \\
Viudos/as & 20,3 & 8,4 & 14,9 \\
Bilbao & 39,3 & 50,1 & 43,3 \\
Resto Comarca Gran Bilbao & 44,0 & 33,2 & 40,1 \\
Resto Vizcaya & 16,7 & 16,8 & 16,5 \\
Total & 100 & 100 & 100 \\
\% Nacionalidad & 65 & 28 & 100 \\
\hline
\end{tabular}

$7,3 \%$ no consta nacionalidad y $0,2 \%$ no consta edad.

Fuente: Elaboración propia sobre bases Diputación Foral de Bizkaia (DBF). 
res casi todas). Entre los perceptores españoles estas dos situaciones abarcan, respectivamente, un $20 \%$ y un $22 \%$ de los titulares.

- Existe también una importante diferencia en cuanto a la distribución territorial de los perceptores españoles y extranjeros: aunque en ambos casos el $83 \%$ está radicado en la comarca metropolitana del Gran Bilbao, los perceptores extranjeros están básicamente concentrados en el municipio de Bilbao (la mitad del total) mientras que entre los españoles los que residen en el resto de los municipios metropolitanos suman el $44 \%$. Entre los extranjeros, sumando a los residentes en Bilbao, los de los municipios de Barakaldo, Santurtzi, Getxo, Sestao, Erandio y Leioa ya suponen el $75 \%$ de los perceptores extranjeros.

\section{Antigüedad, estancia y continuidad en la prestación. Comparación}

Dadas las características originales de los datos (cómputo de fechas para las resoluciones) y la consideración a priori de un periodo acumulado de 6 años y medio para la descripción, no puede establecerse un solo indicador que mida el "tiempo" que llevan los perceptores en el sistema, ya que ello depende mucho de cómo se contabilice. La intención inicial era conseguir elaborar alguna medida que permitiera identificar estancias más o menos "largas" o "cortas" en relación al periodo contemplado. Para ello, se trabajó primero con los años de entrada y posteriormente con el número de mensualidades cobradas hasta elaborar un "Índice de Continuidad".

Como primera aproximación podemos recurrir a la distribución de perceptores según los Años de "entrada" a la prestación, definidos como el año en el que cada perceptor cobra por primera vez una prestación dentro de este periodo (a cuenta de solicitudes abiertas también dentro del periodo). En segundo lugar, se puede utilizar el indicador agregado de Suma de pagos mensuales percibidos como otra forma algo más específica para computar los "tiempos de estancia" en la prestación.

Para medir la continuidad se ha elaborado un índice de continuidad que computa la relación entre los meses de prestación percibidos y los meses exactos transcurridos desde la entrada en el sistema hasta mayo de 2010. Expresado en una tasa porcentual nos permite clasificar a los perceptores por niveles, desde los que tienen una presencia más puntual u "ocasional" (que han cobrado como mucho un tercio de los meses transcurridos desde que entraron) hasta los totalmente "continuos" (que estuvieron percibiendo la prestación ininterrumpidamente desde que entraron en el sistema y hasta la fecha de cierre de los datos).

$$
\text { Índice de Continuidad }=\frac{N^{0} \text { MensualidadesPercibidas }}{N^{0} \text { MesesTranscurridos }} * 100
$$

A efectos del análisis de estas características de las prestaciones se han eliminado a los perceptores de más de 64 años, ya que su volumen entre la población española, 
especialmente a partir de 2009, distorsiona la comparación con la población extranjera. El hecho es que a cuenta de un cambio en los criterios de acceso a RGI en Vizcaya en 2008, personas pensionistas de más de 64 años podían obtener por esta vía compensación a sus pensiones no contributivas, lo que compone un perfil muy específico de beneficiario de RGI en el caso de las mujeres viudas con una RGI de cuantía muy baja.

En términos de antigüedad en la "entrada" (tabla 5), la distribución de españoles y extranjeros es lógicamente diferente, debido al ritmo de los flujos de inmigración en este periodo, y los datos obtenidos así lo reflejan. Por otra parte, prácticamente todos los perceptores extranjeros (98\%) que aparecen en este periodo son nuevos, mientras que entre los españoles los ingresos realmente nuevos solo suponen el $54 \%$ del total, es decir, el $46 \%$ restante son perceptores que ya estaban o estuvieron en algún momento en el sistema antes de 2004. Considerando solo a los perceptores nuevos, la mayoría de estos entró en el sistema a partir de 2007 aunque su peso es más importante entre los extranjeros (70\%) que entre los españoles (59\%). El ritmo de nuevas entradas está bastante más repartido entre los españoles que entre los extranjeros, lo cual también es coherente con la evolución de la llegada y presencia de estos últimos entre la población.

Una forma más específica de computar el "tiempo de estancia" en la prestación es contabilizar el número de mensualidades efectivamente percibidas a cuenta de las resoluciones abiertas desde enero 2004. En total, el tiempo máximo de estancia para el periodo de análisis contemplado sería de 77 meses (cobrando hasta el mes de mayo de 2010, último mes completo a cierre de datos de la base) para algún perceptor que hubiera permanecido recibiendo la prestación de modo consecutivo durante todo el periodo considerado.

Tabla 5.

Perceptores por Año de Entrada y según Nacionalidad (\%)

\begin{tabular}{l|c|c|c|c|c|c|c}
\hline \multicolumn{3}{c}{ Nuevos desde 2004 } & \multirow{2}{*}{ Total 2004/2010 } \\
\cline { 1 - 6 } Año Entrada & Española & Extranjera & Total & Española & Extranjera & Total & Nuevos 04 \\
\hline 2004 & 11,4 & 1,6 & 10,4 & 25,5 & 2,4 & 20,8 & 33,7 \\
2005 & 15,4 & 12,5 & 13,5 & 18,5 & 12,8 & 16,8 & 54,2 \\
2006 & 13,8 & 15,9 & 14,2 & 13,6 & 15,7 & 13,8 & 69,4 \\
2007 & 12,1 & 17,6 & 14,2 & 10,8 & 17,3 & 12,5 & 76,6 \\
2008 & 11,8 & 18,4 & 14,6 & 8,5 & 18,1 & 11,2 & 87,7 \\
2009 & 21,2 & 22,0 & 20,6 & 14,1 & 21,7 & 15,6 & 88,9 \\
2010 (hasta Mayo) & 14,3 & 12,1 & 12,5 & 9,0 & 11,9 & 9,2 & 91,6 \\
Total & 100 & 100 & 100 & 100 & 100 & 100 & 67,5 \\
\% Nacionalidad & 45 & 55 & 100 & 57 & 34 & 100 & \\
\hline
\end{tabular}

Total 2004/2010 incluye 9\% no consta nacionalidad. Descontando edad $>64$.

Fuente: Elaboración propia sobre bases Diputación Foral de Bizkaia (DBF). 
Los datos (tabla 6) muestran que hay perceptores en todas las situaciones posibles (cobrando entre 1 y 77 meses), lo cual se corresponde con los diferentes "momentos" de entrada y con el número agregado y la duración variable de cada resolución. La distribución de los perceptores en esta característica es muy heterogénea y considerablemente asimétrica: la mitad de los titulares ha cobrado como mucho 2 años de prestación (24 meses mediana) y la otra mitad entre 2 y 6 años y medio, aunque hay una cuarta parte de estancias "más largas" que se cuentan a partir de los 44 meses (más de 3 años y medio). El promedio de 28 meses refleja el mayor peso de perceptores de estancia "más corta". La comparación de resultados entre españoles y extranjeros refleja que como colectivo, evidentemente, los extranjeros tienen una estancia menor ya que por su ritmo de entrada hay menos extranjeros que hayan podido cubrir todo el periodo en la prestación. Por otra parte, un análisis comparado en función de la presencia previa en el sistema también desvela la importancia de diferenciar a los perceptores realmente nuevos desde 2004 de los que ya estuvieron antes en el sistema y, en general, la relevancia de considerar los ritmos de entrada.

Tabla 6.

Perceptores por Suma de Pagos Mensuales (\%) y según Nacionalidad

\begin{tabular}{lccc}
\hline Suma pagos mensuales & Española & Extranjera & Total \\
\hline 1-12 meses (hasta 1 año) & 31,9 & 36,4 & 32,1 \\
13-24 meses & 16,3 & 22,5 & 18,5 \\
$25-36$ meses & 13,1 & 19,3 & 15,4 \\
$37-48$ meses & 13,0 & 12,8 & 12,9 \\
$49-60$ meses & 10,7 & 7,1 & 9,7 \\
61-72 meses & 11,1 & 1,9 & 8,7 \\
73-77 meses (más de 6 años) & 3,8 & 0,0 & 2,6 \\
Total & 100 & 100 & 100 \\
$\%$ Nacionalidad & 57 & 34 & 100 \\
\hline Media & 30,3 & 22,6 & 28,4 \\
Mediana & 26 & 20 & 24 \\
Percentil25 & 10 & 9 & 10 \\
Percentil75 & 49 & 34 & 44 \\
Desv. Típica & 22,9 & 16,5 & 21,4 \\
Coef. Variación \% & 76 & 73 & 75 \\
\hline
\end{tabular}

Total incluye $9 \%$ no consta nacionalidad. Descontando edad $>64$.

Fuente: Elaboración propia sobre bases Diputación Foral de Bizkaia (DBF). 
Como se ha mencionado (tabla 7), el Índice de Continuidad elaborado pone en relación los meses de prestación percibidos con el tiempo transcurrido, de manera que permite identificar un extremo de máxima continuidad que es muy importante para la consideración de las situaciones de cronicidad.

A este respecto la situación global es bastante interesante, ya que sobre el conjunto de los perceptores (y eliminando las rentas compensatorias) prácticamente la mitad $(48 \%)$ de las personas perceptoras habría cobrado ininterrumpidamente la prestación durante su estancia. La calificación de la agrupación utilizada (ocasional, "intermitente", habitual, continua) es tentativa y no debe malinterpretarse, ya que no permite discriminar todos los tipos de variaciones de duración de la estancia.

Tanto entre los titulares españoles como entre los extranjeros, el grupo de perceptores más numeroso es el de máxima continuidad, aunque la tasa es mayor entre los extranjeros $(53,5 \%)$ que entre los españoles $(49 \%)$. Como la continuidad es más probable para las estancias más recientes y entre los españoles hay más perceptores de entrada antigua y no nuevos del periodo, comparamos también las tasas solo para los perceptores nuevos. Para este sector, la tasa de máxima continuidad es claramente mayoritaria en ambos casos y ligeramente mayor entre los españoles $(55,6 \%)$ que entre los extranjeros $(54,2 \%)$, aunque entre los españoles sigue habiendo mayor variedad de situaciones y también es mayor el grupo de muy baja continuidad ("ocasionales").

Tabla 7.

Índice de Continuidad según Nacionalidad y trayectoria anterior

\begin{tabular}{l|c|c|c|c|c|c}
\hline & \multicolumn{3}{|c|}{ Nuevos desde 2004 } & \multicolumn{3}{c}{ Total 2004/2010 } \\
\hline & Española & Extranjera & Total & Española & Extranjera & Total \\
\hline $1-33 \%$ (Ocasional) & 17,0 & 11,0 & 14,9 & 18,2 & 11,2 & 16,6 \\
$34-66 \%$ (Intermitente) & 12,2 & 12,1 & 12,8 & 14,0 & 12,5 & 14,2 \\
$67-99 \%$ (Habitual) & 15,3 & 22,6 & 19,4 & 18,7 & 22,8 & 20,7 \\
$100 \%$ (CONTINUO) & 55,6 & 54,2 & 53,0 & 49,1 & 53,5 & 48,5 \\
Total & 100 & 100 & 100 & 100 & 100 & 100 \\
\% Nacionalidad & 45 & 50 & 100 & 57 & 34 & 100 \\
\% Nuevos 2004 sobre total & 53 & 98 & 67 & & & \\
\hline
\end{tabular}

Total incluye $9 \%$ que no consta nacionalidad.

Descontando edad $>64$ y $2,3 \%$ no calculable.

Fuente: Elaboración propia sobre bases Diputación Foral de Bizkaia (DBF). 


\section{Cobertura y cuantía de la prestación. Comparación}

Respecto al alcance económico de las prestaciones recibidas y siempre sobre la base de la información disponible, se ha trabajado sobre dos indicadores: la tasa de cobertura promedio de las prestaciones recibidas y la cuantía mensual promedio de las prestaciones percibidas.

La tasa media de cobertura de las prestaciones recibidas a lo largo del periodo 20042010 es una ratio (\%) entre el importe concedido (y recibido) y el máximo posible que se concedería en la situación peor de ingresos ${ }^{2}$. La tasa es un cómputo agregado que puede contener la combinación de situaciones de cobertura diferentes a lo largo de las estancias de los perceptores, pero sobre todo es interesante para discriminar la situación extrema de máxima cobertura.

La cuantía mensual promedio de la prestación es simplemente la media de todos los ingresos percibidos durante la estancia (o estancias) en la prestación. Este indicador en realidad solo informa de la situación agregada del grueso del contingente de perceptores (69\%), ya que además de la eliminación de las rentas compensatorias, debido a la agregación de datos, ha habido que filtrar la información relativa a los casos más extremos y a casos atípicos, cuyos promedios calculados resultan manifiestamente afectados por cuestiones de contabilidad original de la información.

Respecto a las tasas de cobertura (tabla 8), y para el conjunto contemplado de perceptores, lo más destacable es que la variedad de situaciones es altísima, cubriendo prácticamente todo el espectro posible: desde ingresar menos de un 10\% del máximo potencial hasta cobrar la máxima prestación que en cada caso contempla la RGI. Como dato-resumen, el promedio de cobertura para el conjunto de los perceptores (descontando rentas compensatorias) estaría en un $73 \%$, fundamentalmente porque el grupo más numeroso, con diferencia, es el que durante su estancia en la prestación ha cobrado siempre el tope ( $100 \%$ de cobertura): un $37 \%$ de los perceptores ha estado en esta situación de cobertura total.

Con relación a la cuantía promedio (tabla 9) de la prestación recibida a lo largo de su estancia, para la mayoría de los perceptores la prestación promedio resultaría de 575 euros/mes, de manera que prácticamente la mitad habría percibido entre 100 y 600 y la otra mitad más de 600 euros/mes (hasta 1000) como media de su estancia en el sistema de RGI. En realidad, la distribución de cuantías es bastante equilibrada alrededor de este promedio.

\footnotetext{
${ }^{2}$ En este periodo, las aportaciones máximas de RGI definidas a partir de los datos de las resoluciones de los perceptores han oscilado entre los 426 y los casi 1000 euros/mes. El umbral máximo ha permanecido constante a lo largo del periodo 2004-2010, pero el umbral mínimo se ha ido incrementando desde los 426 euros de 2004 hasta los 650 de 2010 como consecuencia, sobre todo, del incremento del Salario Mínimo Interprofesional. En estos momentos la RGI supone el $88 \%$ del SMI para una Unidad de Convivencia Unipersonal.
} 
Aun tratándose de indicadores agregados para todo el periodo 2004-2010 y con todas las salvedades metodológicas hechas anteriormente, queda de manifiesto que, en general, tanto los niveles de cobertura (tabla 8) como la cuantía de las prestaciones (Tabla 9) de los extranjeros son mayores que la de los españoles. En general, la clave de las diferencias está en la mayor "homogeneidad" de situaciones dentro del colectivo extranjero frente a una mayor variedad en el colectivo español.

Entre los extranjeros son mayoría los que dependen totalmente de la RGI, ya que casi el $53 \%$ se sitúa en la tasa de cobertura total $(100 \%)$ mientras ha estado en la prestación. En consecuencia, el promedio de los ingresos mensuales está en 676 euros/mes dado que más del $70 \%$ de los extranjeros ha tenido rentas mensuales promedio de 600 euros o más.

Entre los españoles, y habiendo descontado las rentas de compensación, solo el $28 \%$ de los perceptores ha estado siempre en la situación de máxima cobertura y la presencia bastante repartida en los diferentes niveles apunta a trayectorias y estancias mucho más variadas. Así el importe mensual promedio (522 euros/mes) es 150 euros menor que el de los extranjeros porque al haber mucha más dispersión también son muchos menos los que han tenido ingresos más altos (solo el $40 \%$ cobra rentas de 600 y más).

Tabla 8.

Tasas de Cobertura por Nacionalidad (descontando mayores de 64 años)

\begin{tabular}{lccc}
\hline & Española & Extranjera & Total \\
\hline $1-25 \%$ & 10,7 & 2,7 & 7,2 \\
$26-50 \%$ & 23,7 & 7,2 & 16,8 \\
$51-75 \%$ & 22,9 & 17,5 & 21,6 \\
$76-99 \%$ & 14,5 & 20,0 & 17,7 \\
$100 \%$ & 28,2 & 52,6 & 36,6 \\
Total & 100 & 100 & 100 \\
$\%$ Nacionalidad & 57 & 34 & 100 \\
Media & 66 & 84 & 73 \\
Mediana & 66 & 100 & 79 \\
Percentil25 & 42 & 72 & 51 \\
Percentil75 & 100 & 100 & 100 \\
Desv. Típica & 29 & 22 & 28 \\
Coef. Variación \% & 44 & 27 & 38 \\
\hline
\end{tabular}

Total incluye el $9 \%$ que no consta nacionalidad. Descontando Edad $>64$.

Fuente: Elaboración propia sobre bases Diputación Foral de Bizkaia (DBF). 
Tabla 9.

Perceptores por Cuantía Mensual Promedio según Nacionalidad (descontando mayores de 64 años)

\begin{tabular}{lccc}
\hline Cuantía $€$ & Española & Extranjera & Total \\
\hline $100-199$ & 9,4 & 1,7 & 6,3 \\
$200-299$ & 11,5 & 2,7 & 8,1 \\
$300-399$ & 10,5 & 4,1 & 8,3 \\
$400-499$ & 11,6 & 6,5 & 10,3 \\
$500-599$ & 17,5 & 12,5 & 16,7 \\
$600-699$ & 17,2 & 26,6 & 20,4 \\
$700-799$ & 10,5 & 18,2 & 13,4 \\
$800-899$ & 8,4 & 17,7 & 11,2 \\
$900-1000$ & 3,5 & 9,9 & 5,3 \\
Total & 100 & 100 & 100 \\
$\%$ Nacionalidad & 58 & 32 & 100 \\
\hline Media & 522 & 676 & 575 \\
Mediana & 547 & 679 & 601 \\
Percentil25 & 340 & 585 & 424 \\
Percentil75 & 679 & 813 & 736 \\
Desv. Típica & 221 & 181 & 216 \\
Coef. Variación \% & 42 & 27 & 27 \\
\hline
\end{tabular}

Total incluye el $10 \%$ que no consta nacionalidad.

Descontando edad $>64$ y casos atípicos, computado para el $69 \%$.

Fuente: Elaboración propia sobre bases Diputación Foral de Bizkaia (DBF).

\section{Aproximación a medidas de cronicidad}

El trabajo anterior de prueba de indicadores descriptivos de resumen para datos agregados en un cierto periodo de tiempo pone de manifiesto las considerables dificultades para obtener medidas sencillas y fácilmente comparables sobre las características de las personas perceptoras de esta prestación, ya que todos se muestran condicionados por otros aspectos de las trayectorias en la prestación, que la información agregada no puede discriminar. Por otra parte, la alternativa evidente de intentar componer la imagen estática del colectivo en un momento determinado también es metodológicamente compleja de captar, debido a los movimientos de entradas y salidas sobre los cuales no estaba disponible toda la información que se hubiera precisado. 
En cualquier caso, las elaboraciones anteriores fueron componiendo la idea de utilizar combinadamente estos indicadores para crear un índice de cronicidad que permitiera, al menos, detectar 0 asociarse a situaciones de mayor vulnerabilidad social. La idea del perceptor "crónico" es la de un titular que depende en gran medida o totalmente de la prestación y que muestra una permanencia importante en la estancia. Lógicamente, para que eso se dé hay que considerar la reconstrucción de una estancia de cierta antigüedad y, por otra parte, hay que fijar la referencia en un momento determinado y en los perceptores que están realmente activos en ese momento (cobrando a cuenta de una resolución no cerrada). Por simplicidad, el ensayo del índice de cronicidad se realizó para los perceptores activos al final del periodo considerado, mayo de 2010, aunque la opción resultó relevante ya que, del total de titulares distintos analizados de todo el periodo 2004-2010, los que estaban activos en mayo de 2010 eran una mayoría importante $(69 \%)$.

La definición empírica del índice considera "crónicos" en mayo de 2010 a los perceptores activos que, según las elaboraciones anteriores llevan percibiendo la prestación durante tiempo ininterrumpido desde que entraron (continuidad 100\%) y además con cobertura máxima del $100 \%$, es decir, al tope de lo que permite la RGI. Para eliminar a los que obviamente acaban de entrar, y están cobrando de forma estable a cuenta de una primera resolución, se han establecido dos umbrales temporales mínimos de estancia en dos y tres años de duración a contar desde mayo 2010. Evidentemente, los umbrales temporales son una elección y condicionan los resultados cuantitativos, pero creemos que son una referencia mínima que debería discriminar el papel de última red de protección social de la RGI.

Así, los índices de cronicidad calculados para los perceptores activos en 2010 son tasas porcentuales que ponen en relación la cantidad absoluta de perceptores definidos como "crónicos" (a 2 años o a 3 años, en cada caso) con el total de perceptores activos de los que forman parte. En la Tabla 10 se indican también los resultados del índice de cronicidad tomando como base el total de Perceptores distintos del periodo analizado 2004-2010, para que se aprecie qué parte representan estos de todo el contingente descrito anteriormente:

$$
\text { Indice de Cronicidad }=\frac{N^{0} \text { perceptoresCrónicos }}{N^{0} \text { perceptoresActivos }} * 100
$$

Como se deduce (tabla 10), de los perceptores activos en mayo de 2010 hay un grupo de al menos un $9 \%$ de titulares que por lo menos llevaban recibiendo ininterrumpidamente la prestación durante tres años, a los que se añadirían otro 4,5\% que llevaban al menos dos años en esa situación. Es decir, en su definición más laxa, la cronicidad (3 años) alcanza al 13,5\% de los perceptores activos en 2010. Más allá de la valoración cualitativa de estos datos, desde la perspectiva de la función social de la RGI parece que el indicador permite análisis y comparaciones que arrojan luz sobre la realidad. 
El índice de cronicidad más "estricto" ( 3 años) se compone mayoritariamente de perceptores españoles (63\%) pero el menos estricto ( 2 años) empieza a repartirse más entre españoles y extranjeros (58\%/42\%). Teniendo en cuenta que la proporción de extranjeros entre los perceptores activos en mayo de 2010 es claramente minoritaria $(28 \%)$, la incidencia de este tipo de permanencia en algún grado entre los extranjeros es comparativamente importante: afecta a un $15 \%$ de los perceptores activos.

El indicador puede aplicarse a cualquier subgrupo de perceptores a efectos comparativos y también puede analizarse la distribución de perfiles característicos entre los perceptores crónicos, con lo que pueden detectarse los ejes-clave de la vulnerabilidad social con referencia a un momento determinado.

En el marco de este primer análisis descubrimos, por ejemplo, que entre los perceptores crónicos hay todo tipo de perfiles sociodemográficos, a excepción de personas que entraron mayores en la prestación. Más bien al contrario, la mayoría son titulares que entraron en la prestación con 25-44 años y también la gran mayoría son solteros. Esto sucede tanto entre hombres como entre mujeres aunque, por su peso en el conjunto, hay más mujeres titulares en esta situación. En consecuencia y a efectos comparativos (tabla 11) las tasas de permanencia o cronicidad más destacadas entre la población española estaban entre los grupos más jóvenes, los solteros y los titulares hombres. Entre los extranjeros, sin embargo, destacan más las tasas de los perceptores que entraron con más de 44 años.

Tabla 10.

Índices de Cronicidad (\%) en Mayo 2010 según Nacionalidad*

\begin{tabular}{|c|c|c|c|c|c|c|}
\hline \multirow[b]{3}{*}{ Crónicos } & \multirow{2}{*}{\multicolumn{3}{|c|}{$\begin{array}{l}\text { Cronicidad a } 2 \text { años (min) } \\
\text { Entra Mayo } 2008 \text { o antes }\end{array}$}} & \multirow{2}{*}{\multicolumn{3}{|c|}{$\begin{array}{l}\text { Cronicidad a } 3 \text { años (min) } \\
\text { Entra Mayo } 2007 \text { o antes }\end{array}$}} \\
\hline & & & & & & \\
\hline & Española & Extranjera & Total & Española & Extranjera & Total \\
\hline $\begin{array}{l}\text { Distribución de crónicos por } \\
\text { nacionalidad }\end{array}$ & 52,5 & 42,1 & 100 & 63,5 & 28,9 & 100 \\
\hline \% sobre Total Activos Mayo 2010 & 8,1 & 15,0 & 10,2 & 6,5 & 6,9 & 6,8 \\
\hline $\begin{array}{l}\text { \% sobre Total Activos Mayo } 2010 \\
\text { (descontando edad>64) }\end{array}$ & 12,5 & 15,2 & 13,5 & 10,1 & 7,0 & 9,0 \\
\hline $\begin{array}{l}\text { \% sobre Perceptores distintos } \\
2004 / 2010\end{array}$ & 5,7 & 10,7 & 7,1 & 4,6 & 4,9 & 4,7 \\
\hline $\begin{array}{l}\text { \% sobre Perceptores distintos } \\
2004 / 2010 \text { (descontando edad }>64 \text { ) }\end{array}$ & 8,2 & 10,8 & 8,9 & 6,6 & 4,9 & 5,9 \\
\hline
\end{tabular}

*Entre $5 \%$ y $7,5 \%$ no consta nacionalidad.

Fuente: Elaboración propia sobre bases Diputación Foral de Bizkaia (DBF). 
Entre los extranjeros (tablas 12 y 13) destaca asimismo la sobrerrepresentación de los africanos subsaharianos que constituyen casi el $20 \%$ de todos los extranjeros en esta situación de cronicidad, mientras que solo representan un $15 \%$ del total de perceptores extranjeros activos en mayo de 2010. También los perceptores de Rumanía muestran una cierta tendencia a cronificarse en la prestación, aunque su representación en volumen sea mucho menor. Por el contrario, el grupo latinoamericano es el que tiene una presencia en el indicador de cronicidad inferior a su peso sobre el total de los extranjeros activos en 2010: aún siendo el grupo más numeroso, entre los extranjeros en situación de cronicidad hay un $48 \%$ de latinoamericanos, cuando su presencia en el conjunto del contingente extran-

Tabla 11.

Índices de Cronicidad (\%) activos Mayo 2010 según nacionalidad y por subgrupos

\begin{tabular}{|c|c|c|c|}
\hline & & $\begin{array}{l}\text { Índice Cronicidad a } 2 \text { años } \\
\text { (Mayo } 2008 \text { o antes) }\end{array}$ & $\begin{array}{l}\text { Índice Cronicidad a } 3 \text { años } \\
\text { (Mayo } 2007 \text { o antes) }\end{array}$ \\
\hline \multirow{10}{*}{ 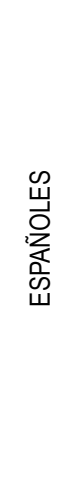 } & Mujeres & 11,7 & 9,3 \\
\hline & Hombres & 14,1 & 11,3 \\
\hline & 18-24 años & 22,6 & 16,6 \\
\hline & 25-34 años & 14,8 & 11,8 \\
\hline & 35-44 años & 11,8 & 9,5 \\
\hline & 45-54 años & 12,1 & 10,3 \\
\hline & $55-64$ años & 6,4 & 5,2 \\
\hline & Solteros & 15,2 & 12,0 \\
\hline & Casados y uniones & 12,0 & 10,3 \\
\hline & Divorciados y separados & 9,7 & 7,9 \\
\hline \multicolumn{2}{|c|}{ Índice global } & 12,5 & 10,1 \\
\hline \multirow{10}{*}{ 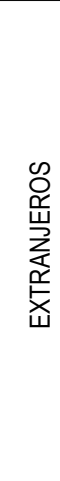 } & Mujeres & 14,5 & 6,9 \\
\hline & Hombres & 16,0 & 7,0 \\
\hline & 18-24 años & 15,9 & 6,7 \\
\hline & 25-34 años & 14,8 & 6,3 \\
\hline & 35-44 años & 14,6 & 7,4 \\
\hline & 45-54 años & 15,5 & 8,4 \\
\hline & 55-64 años & 20,3 & 9,0 \\
\hline & Solteros/as & 16,5 & 7,4 \\
\hline & Casados y uniones & 12,8 & 6,0 \\
\hline & Divorciados y separados & 11,6 & 6,4 \\
\hline \multicolumn{2}{|c|}{ Índice global } & 15,2 & 6,9 \\
\hline
\end{tabular}

Descontando edad $>64$.

Fuente: Elaboración propia sobre bases Diputación Foral de Bizkaia (DBF). 
jero es de un $55 \%$. Este tipo de diferencias se aprecian y se especifican comparando los índices de cronicidad concretos de las principales nacionalidades (tabla 13): en ambas versiones del índice los colectivos nacionales que ocupan las posiciones más desfavorables (por encima de la media del contingente extranjero) son los mismos e incluyen con claridad a los perceptores rumanos, a los senegaleses (principal representación del África subsahariana), a los argelinos, y a un único contingente (pequeño) latinoamericano, los perceptores de Brasil. Como se ve, las principales (en volumen) nacionalidades latinoamericanas (Bolivia y Colombia) y las de llegada más reciente (Paraguay) quedan por debajo del índice global de los extranjeros, así como también el contingente de titulares de Marruecos.

Tabla 12.

Distribución de crónicos extranjeros y de activos extranjeros en Mayo 2010 por áreas de nacionalidad

\begin{tabular}{lcc}
\hline & \% Crónicos a 2 años & \% Activos Mayo 2010 \\
\hline Latinoamérica & 47,8 & 54,8 \\
Magreb & 15,5 & 16,2 \\
África subshariana & 20,0 & 14,9 \\
Rumanía & 10,5 & 8,8 \\
Asia & 1,4 & 1,2 \\
Resto & 5,2 & 4,2 \\
Total Extranjeros & 100 & 100 \\
\hline
\end{tabular}

Fuente: Elaboración propia sobre bases Diputación Foral de Bizkaia (DBF).

Tabla 13.

Índices de Cronicidad activos Mayo 2010 para principales nacionalidades extranjeras

\begin{tabular}{lcc}
\hline & $\begin{array}{c}\text { Índice Cronicidad a 2 años } \\
\text { (Mayo 2008 o antes) }\end{array}$ & $\begin{array}{c}\text { Índice Cronicidad a } 3 \text { años } \\
\text { (Mayo 2007 o antes) }\end{array}$ \\
\hline Bolivia & 13,2 & 4,3 \\
Marruecos & 12,0 & 4,9 \\
Colombia & 11,9 & 6,6 \\
Rumanía & 17,9 & 11,2 \\
Senegal & 17,9 & 5,4 \\
Brasil & 19,2 & 9,4 \\
Argelia & 18,1 & 7,6 \\
Paraguay & 10,6 & 3,4 \\
Total Extranjeros & 15,2 & 6,9 \\
\hline
\end{tabular}

Descontando edad $>64$. Nacionalidades con más de 400 perceptores activos mayo 2010

Fuente: Elaboración propia sobre bases Diputación Foral de Bizkaia (DBF). 


\section{CONCLUSIONES Y DISCUSIÓN}

Recapitulando los principales hallazgos obtenidos se puede concluir que, con respecto a las características generales de los titulares perceptores de RGI en Vizcaya 2004-2010, es destacable que los resultados aportados aquí coinciden en gran parte con otros estudios que también han intentado captar los perfiles y tipologías de las personas perceptoras de RGI; y tanto referidos a la CAPV (Gobierno Vasco 2008), como a nivel estatal (Consejo Económico y Social 2002; Coll 2004) o internacional (Mandin y Palier 2003; Busilacchi 2008; Frazer y Marlier 2009). Así, junto a una clara concentración urbana, que en este caso se da en la comarca del Gran Bilbao y muy especialmente en la propia capital -Bilbao-, aparecen otros elementos definitorios, como el mayor peso de las mujeres entre los perceptores titulares, la relativa juventud de las personas titulares de la prestación o el mayor peso del colectivo inmigrante entre los perceptores si tenemos en cuenta su peso sobre el total de la población.

Además, los análisis realizados han permitido avanzar bastante más en la comparación de características entre el colectivo autóctono y el extranjero como perceptores de RGI. Puede subrayarse, por ejemplo, el perfil diferencial por edad y sexo: las personas perceptoras extranjeras son sensiblemente más jóvenes y en términos relativos hay un mayor peso de hombres, dándose además entre los extranjeros una todavía mayor concentración espacial, sobre todo en el municipio de Bilbao.

Con respecto a aspectos como la cuantía o la permanencia en la prestación, parece detectarse con mucha claridad que el colectivo extranjero percibe tanto un mayor nivel de cobertura como de cuantía, lo cual indica su mayor vulnerabilidad. Es clave que entre la población autóctona hay mucha mayor variedad de situaciones en cuanto a cobertura y cuantía, lo que sugiere la existencia también de muy diversas formas de combinación y compensación de rentas contributivas o de relación de los titulares con el mercado laboral. En el caso de los extranjeros, en cambio, parece detectarse que son más los que no tienen ningún tipo de ingreso adicional y por lo tanto se sitúan en coberturas y cuantías más altas.

Dadas las dificultades metodológicas de medición de la duración de las estancias no ha sido posible ser muy tajantes en las conclusiones al respecto. Al trabajar con datos agregados para un periodo, la influencia de los ritmos de entrada a la prestación es importante pero a efectos comparativos depende de los propios flujos migratorios extranjeros. Los datos parecen indicar que el recurso a la prestación se ha ido incrementando de forma sostenida en estos años para los extranjeros; mientras que, entre los españoles, las intermitencias son bastante importantes. Esta cuestión es una de las que debe seguirse investigando, no obstante.

En todo caso, el uso de los índices de cronicidad a dos y tres años nos permite observar (y comparar) la presencia de un tipo de beneficiario, el perceptor "cronificado" que es de interés tanto analítico como de gestión. El análisis muestra que hay importantes evidencias de una cronificación más acelerada entre el colectivo extranjero, que ya de por si está sobrerrepresentado cuantitativamente en la población perceptora de RGI. A través de este tipo de índice se abunda también en la calificación de algunos colectivos 
nacionales, como es el caso de la población africana subsahariana (Senegal), que es la que sufre en mayor grado situaciones de cronicidad. Este dato se ve parcialmente contrastado a través de otro tipo de estudios, como son las encuestas a la población extranjera, que vienen indicando que el colectivo subsahariano, junto al africano en general, es entre la población extranjera uno de los grupos más vulnerables a nivel estatal (Instituto Nacional de Estadística 2008; Ikuspegi 2010; Observatorio Permanente de la Inmigración en Navarra 2010; Gobierno Vasco 2011).

El estudio que presentamos está acotado a la realidad del País Vasco y en parte está condicionado tanto por las características de su sistema de protección como por los rasgos de su inmigración y su estructura socioeconómica. Por otra parte, el tratamiento metodológico de los datos es absolutamente específico de este análisis, lo cual no permite comparaciones simples de resultados con otros estudios si los hubiera en el ámbito cercano. Sin embargo, creemos que ofrece también algunas conclusiones de interés extrapolables a otros ámbitos geográficos.

En un contexto como el actual, los discursos que inciden y asocian inmigración a uso indebido de prestaciones económicas están erosionando la legitimidad de las políticas sociales en su conjunto y de medidas concretas como las rentas mínimas. De hecho, los programas de rentas mínimas más garantes a nivel estatal, como son el navarro o el vasco, han sufrido serios recortes en los últimos meses y, en ambos, las limitaciones de acceso a la prestación se han focalizado en el colectivo inmigrante. En el caso vasco, desde enero de 2012, uno de los requisitos para obtener la RGI es estar empadronado durante al menos tres años en la CAPV, cuando anteriormente el requisito se reducía a un año. En el caso navarro, las personas extranjeras sin autorización de residencia no pueden solicitar la prestación económica.

En resumidas cuentas, insistiremos en esta línea de trabajo, que adoptará en el futuro una cada vez mayor relevancia en el estudio tanto de las políticas sociales como de la inmigración. Este artículo supone un alto más en el camino y, por citar algunas de las cuestiones que surgen en torno a este debate, es imprescindible indagar en la función y el impacto de las prestaciones sociales sobre el colectivo inmigrante y profundizar en qué medida estas prestaciones son o han sido realmente "un trampolín para la inserción" o pueden convertirse en una "tela de araña para la cronificación de la vulnerabilidad y la exclusión social".

\section{REFERENCIAS BibLIOGRÁFICAS}

Alemán, C. 2010. "Servicios sociales e inmigración en el contexto de crisis económica en España". Pp. 148-163 en La inmigración en tiempos de crisis. Anuario de la inmigración en España, 2009, editado por E. Aja, J. Arango y J. Oliver. Barcelona: CIDOB.

Arriba, A. 1999. "Procesos de implantación de políticas de rentas mínimas de inserción en España", Documento de Trabajo 99-09, Instituto de Políticas y Bienes Públicos (CSIC), en www.iesam.csic. es/doctrab1/dt-99-09.pdf. Consultado el 25/03/2013. 
Arriba, A. 2009. "Rentas Mínimas de Inserción de las Comunidades Autónomas: una visión conjunta de su evolución y alcance". Gestión y Análisis de Políticas Públicas 2:81-89.

Arriba, A. y D. Guinea. 2008. "Protección social, pobreza y exclusión social: el papel de los mecanismos de protección de rentas", en VI. Informe sobre exclusión y desarrollo social en España, 2008, coordinado por Víctor Renes. Madrid: Foessa.

Barr, N. 2004. Economics of the Welfare State. Oxford: Oxford University Press.

Behrendt, C. 2003. "Programas de rentas mínimas y la reducción de la pobreza: ¿una red de seguridad defectuosa? Pp.215-244 en Viejas y nuevas desigualdades: retos para la protección social, coordinado por A. M. Guillén y S. Álvarez García. Madrid: Thomson-Civitas.

Busilacchi, G. 2008. "The different regimes of minimum income policies in the enlarged Europe". Presentado en el XII International Congress of BIEN, 20-21 junio, Dublin. (Disponible en www.basicincome.org/bien/pdf/dublin08/4cigianlucabusilacchibienlargedeurope.doc). Consultado el 8/11/2011.

Cantillon, B. B., N. Van Mechelen y B. Schulte. 2008. "Minimum Income Schemes in Old and New Member States." Pp. 218-234 en Handbook of Quality of Life in the Enlarged EU, editado por T. Faney y C. Saraceno. Londres: Routledge.

Castel, R. 1997. Las metamorfosis de la cuestión social. Una crónica del salariado. Buenos Aires: Paidós.

Cea D’Ancona, M. A. y M. Vallés. S. 2009. Evolución del racismo y la xenofobia en España. Informe 2009. Madrid: Observatorio Español del Racismo y la Xenofobia.

Cea D'Ancona, M. A. y M. S. Vallés. 2010. Evolución del racismo y la xenofobia en España. Informe 2010. Madrid: Observatorio Español del Racismo y la Xenofobia.

Consejo Económico y Social vasco. 2002. Memoria socioeconómica. Comunidad Autónoma del País Vasco. 2001. Bilbao: CES.

Coll, F. 2004. "La Renta Mínima de Inserción Catalana". Presentado en Encuentro Renta Básica y Procesos de Inserción, 1-2 de Diciembre, Vitoria-Gasteiz.

Comisión Europea. 1993. Libro Verde. Política Social. Opciones para la Unión. Luxemburgo: Oficina de Publicaciones de la UE.

Daroit, B. y Ch. Crepaldi. 2007. The role of minimum income for social inclusion in the European Union. Bruselas: European Parliament's Committee on Employment and Social Affairs.

European Comission. 2006. "Concerning a consultation on action at EU level to promote the active inclusion of the people furthest from the labour market". Comunicación presentada a (Disponible en http://eur-lex.europa.eu/LexUriServ/LexUriServ.do?uri=CELEX:52006dc0044:EN:NOT).

European Parliament. 2010. "Are mínimum incomes the answer to poverty and 'working poor'?". European Parliament 29-03-2010. (http://www.europarl.europa.eu/sides/getDoc.do?language=en\&type=IMPRESS\&reference=20100325ST071383). Consultado el 15/12/2011.

Euzéby, Ch. 2004. "La activación francesa de las personas en situación de desempleo y de los beneficiarios de la asistencia pública: entre el workfare anglosajón y la inserción escandinava". Presentado en Encuentro Renta Básica y Procesos de Inserción, 1-2 de diciembre, Vitoria-Gasteiz. (Disponible en www.sergofi.com/gizarteratze/pdf/ponencias/Euzéby.pdf). Consultado el 25/02/2006. 
Euzéby, Ch. 2012. "Social protection to achieve sustainable inclusion: A European imperative in the current economic crisis". International Social Security Review 65:69-88.

Figari, F., T. Haux, M. Matsagani y H. Sutherland. 2010. Coverage and adequacy of Minimum Income in the European Union Research. Bruselas: European Observatory on the Social Situation.

Figari, F. T. Haux, M. Matsagani y H. Sutherland. 2012. "Are European social safety nets tight enough? Coverage and adequacy of Minimum Income Schemes in 14 EU Countries". International Journal of Social Welfare 22:3-14.

Frazer, H. and E. Marliere. 2009. Income Schemes Across EU Member States. Brussels: European Commission. (Disponible en http://www.eesc.europa.eu/resources/docs/minimum-income-schemes-across-eu-member-states_october-2009_en.pdf) Consultado el 20/05/2012.

Gaviria, L. y F. González. 2002. "Propuestas integradas de políticas activas de bienestar y empleo: sumario". Dublín: Fundación Europea para la Mejora de las Condiciones de Vida y de Trabajo. (Disponible en http://www.ceet.es/redinclusionsocial/wp-content/uploads/2011/08/Propuestas-integradasempleo-y-bienestar-Espa\%C3\%B1a.pdf) Consultado el 27/10/2007.

Gobierno Vasco. 1987. La pobreza en la Comunidad Autónoma del País Vasco. Vitoria-Gasteiz: Servicio Central de Publicaciones del Gobierno Vasco.

Gobierno Vasco. 2008. Estudio de las personas perceptoras de Renta Básica. Departamento de Justicia, Empleo y Seguridad Social. Vitoria-Gasteiz: Gobierno Vasco. (Disponible en www.ejgv. euskadi.net/r53-2291/es/contenidos/informe_estudio/renta_basica_evaluacion/es_rentabas/adjuntos/SeguimRentaBasica2007.pdf) Consultado el 4/04/2011.

Gobierno Vasco. 2011. Encuesta de la población inmigrante extranjera residente en la Comunidad Autónoma de Euskadi. Informe general de resultados. Departamento de Empleo y Asuntos Sociales. Vitoria-Gasteiz: Gobierno Vasco. (Disponible en http://www.gizartelan.ejgv.euskadi.net/r45-obpubinm/ es/contenidos/informacion/publicacion_observ_inmigracion/es_publica/adjuntos/EPIE_2010_es.pdf). Consultado el 14/03/2012.

Guibentif, P. y D. Bouget. 1997. Minimum Income Policies in the European Union. Lisboa: European Commission.

Ikuspegi. 2009. Barómetro 2009. Percepciones y actitudes hacia la inmigración extranjera. Bilbao: Ikuspegi-Observatorio Vasco de Inmigración.

Ikuspegi. 2011. Barómetro 2010. Percepciones y actitudes hacia la inmigración extranjera, Bilbao: Ikuspegi-Observatorio Vasco de Inmigración.

Ikuspegi. 2013. Barómetro 2012. Percepciones y actitudes hacia la inmigración extranjera, Bilbao: Ikuspegi-Observatorio Vasco de Inmigración.

Immervoll, H. 2012. "Minimum-income benefits in OECD countries: Policy design, effectiveness and cha-llenges". Pp. 171-209 en Counting the poor: New thinking about European poverty measures and lessons for the Unites States, edited by D. J. Besharov and K. Couch. New York: Oxford University Press.

Instituto Nacional de Estadística. 2008. Encuesta Nacional de Inmigrantes 2007. Madrid: INE.

Laparra, M. 2004. "Las Rentas Mínimas en España". Presentado en Encuentro Renta Básica y Procesos de Inserción, 1-2 Diciembre, Vitoria-Gasteiz. 
Laparra, M. 2004b. "La travesía del desierto de las rentas mínimas en España”. Documentación Social 135:57-76.

Laparra, M. y L. Ayala. 2009. El sistema de garantía de ingresos mínimos en España y la respuesta urgente que requiere la crisis social. Madrid: Fundación Foessa.

Mandin, Ch. y B. Palier. 2003. "Policy Maps. France". Working Paper (WRAMSOC project), University of Kent, Kent. (Disponible en www.kent.ac.uk/wramsoc/workinpapers/secondyearsreport/policymaps/ francepolicymaps.pdf). Consultado el 22/05/2012.

Marchal, S. I. Marx and N. Van Mechelen. 2011. "Do Europe's Minimum Income Schemes Provide Adequates Shelter against the Economic Crisis and How, if at all, Have Gobernments Respondes?". IZA Discussion Paper series n. ${ }^{\circ}$ 6264, Institute for the Study of Labor, Bonn. (Disponible en http:// ftp.iza.org/dp6264.pdf). Consultado el 24/05/2012.

Matsaganis, M., M. Ferrera, L. Capucha y L. Moreno. 2003. "Mending nets in the South: Anti-poverty policies in Greece, Italy, Portugal and Spain". Social Policy and Administration 37:639-655.

Moreno, G. y X. Aierdi. 2008. "Inmigración y servicios sociales: ¿última red o primer trampolín?". Zerbitzuan 44:7-18.

Ministerio de Trabajo y Asuntos Sociales. 2005. Secretaría de Estado de Servicios Sociales, Familias y Discapacidad. "III Plan Nacional de Acción para la Inclusión Social del Reino de España. 20052006". Madrid: Ministerio de Trabajo y Asuntos Sociales. (Disponible en www.mtas.es/SGAS/ServiciosSocDep/inclusionsocial/plannacional/IIIPNAin.pdf). Consultado el 07/09/2011.

Moreno, L., M. Matsaganis, M. Ferreira y L. Capucha. 2003. "Existe una malla de seguridad en la Europa del sur". Revista Internacional de Sociología 36: 7-31.

Nelson, K. 2010. "Social assistance and minimum income benefits in old an new democracies". International Journal of social Welfare 19:367-378.

Pamplona: Gobierno de Navarra. 2010. Oficina de Atención a la Inmigración. http://www.navarra.es/NR/ rdonlyres/CA7C7E3F-BC58-444A-B69A-8CF482E1D311/183390/la_incidencia_de_la_crisis.pdf

Peña-Casas, R. 2005. "Minimum income standars in enlarged UE. Guaranteed Minimum Income Schemes in EU." (Disponible en www.eapn.ie/pdfs/155_paper\%20II\%20-\%20Minimum\%20 income\%20standards\%20in\%20enlarged\%20EU.pdf). Consultado el 18/04/2012.

Rat, C. 2009. "The impact of minimum income guarantee schemes in Central and Eastern Europe". Pp. 164-181 in Post-communist welfare pathways: Theorizing social policy transformations in CEE, edited by A. Cerami and P. Vanhuysee. Basingstoke: Palgrave Macmillan.

Rinken, S. y M. Pérez Yruela. 2007. Opiniones y actitudes de la población andaluza ante la inmigración. Sevilla: Junta de Andalucía.

Rinken, S. et al. 2009. Opiniones y actitudes de los andaluces ante la inmigración II. Entre la estabilidad y el cambio. Sevilla: Junta de Andalucía.

Roberts, E. 2001. "Coordination of activation programmes for minimum income recipients. European experiences: a synthesis", Paper presented in the Workshop "Social Exclusion, minimum income support and workfare in Europe", at the $5^{\text {th }}$ Conference Visions and Divisions of the European Sociological Association, 28 agosto-1 septiembre, Helsinki. (Disponible en http:/l shiva.uniurb.it/EUREX/esa/PDF/ESA-Roberts.pdf). Consultado el 7/11/2011. 
Rodríguez Cabrero, G. 2009. "Valoración de los programas de rentas mínimas en España”. Brussels: European Commission- DG Employment, Social Affairs \& Inclusion. (Disponible en www.eapn-galicia. com/archivos/067_--valoracion-programas-rentas-minimas-espana.pdf). Consultado el 19/04/12.

Saraceno, C. 2010. "Concepts and Practices of Social Citizenship in Europe: The case of poverty and income support for the poor". Pp.151-175 in United in Diversity? Comparing social Models in Europe and America, edited by J. Alber y N. Gilbert. Oxford: Oxford University Press.

Van Mechelen, N., S. Marchal, T. Goedemé, I. Marx and B. Cantillon. 2011. "The CSB-Minimum Income Protection Indicators dataset". CSB Working Paper 11/05, University of Antwerp, Antwerp.

Yacut-Cakar, B., B. Erus y F. Adaman. 2012. "An inquiry on introducing a mínimum income scheme in Turkey: Alternating between cost efficiency and poverty reduction". Journal of European Social Policy 22:305-318.

Cristina Lavia Martínez es Doctora por la Universidad de Deusto. Profesora Titular en el Departamento de Sociología y Trabajo Social de la Universidad del País Vasco, especializada en metodología y análisis cuantitativo aplicado a las ciencias sociales. Colabora en proyectos de investigación sobre innovación y sistemas I+D, así como en el desarrollo y análisis de indicadores sociales.

Gorka Moreno Márquez es Doctor por la Universidad del País Vasco. Profesor Agregado en el Departamento de Sociología y Trabajo Social de la Universidad del País Vasco. Sus líneas de investigación y publicación se concentran en los ámbitos de la exclusión social, las políticas sociales y la inmigración. Actualmente es Director de Ikuspegi@k-Observatorio Vasco de Inmigración.

Xabier Aierdi Urraza es Doctor por la Universidad de Deusto. Profesor Titular en el Departamento de Sociología y Trabajo Social de la Universidad del País Vasco. Sus líneas de investigación y publicación se concentran en los ámbitos de la etnicidad y la identidad, la exclusión, la inmigración y las políticas sociales.

RECIBIDO: 23/01/2013

ACEPTADO: 04/07/2013

PUBLICADO ONLINE: 21/07/2014 